\title{
Preventive Effect of Rebamipide Gargle on Chemoradiotherpy- Induced Oral Mucositis in Patients with Oral Cancer: a Pilot Study
}

\author{
Takashi Yasuda ${ }^{1}$, Hiroshige Chiba ${ }^{1}$, Takafumi Satomi ${ }^{1}$, Akira Matsuo ${ }^{1}$, Tadayoshi Kaneko ${ }^{1}$, Daichi \\ Chikazu$^{1}$, Hironobu Miyamatsu²
}

${ }^{1}$ Department of Oral and Maxillofacial Surgery, Tokyo Medical University, Tokyo, Japan.

${ }^{2}$ Department of Pharmacy, Tokyo Medical University Hospital, Tokyo, Japan.

\author{
Corresponding Author: \\ Takashi Yasuda \\ Department of Oral and Maxillofacial Surgery, Tokyo Medical University \\ 6-7-1 Nishi-Shinjuku, Shinjuku-ku, Tokyo \\ Japan \\ Phone: $+81-3-3342-6111$ \\ Fax: +81-3-3342-1723 \\ E-mail: t-yasu@tokyo-med.ac.jp
}

\begin{abstract}
Objectives: To assess the efficacy and safety of rebamipide in preventing chemoradiotherapy-induced oral mucositis in patients with oral cancer.

Material and Methods: Patients with oral cancer treated with chemoradiotherapy (daily radiotherapy plus docetaxel hydrate once a week) were enrolled for this study. They were assigned in a double-blind fashion to receive either rebamipide gargle or placebo on the days of chemoradiotherapy. Oral mucositis was assessed using the WHO grading system. The primary endpoint of this study was the incidence of grade 3 - 4 mucositis after exposure to 40 Gy radiation (4 weeks). The secondary endpoint was the effect of rebamipide gargle on tumour response to chemoradiotherapy.

Results: Twenty-four patients were randomly assigned to receive rebamipide gargle $(\mathrm{n}=12)$ or placebo-gargle $(\mathrm{n}=12)$ during chemoradiotherapy. The number of patients with severe mucositis (WHO $\geq 3$ ) was higher in the placebo group than in the rebamipide group $(83.3 \%$ vs. $33.3 \%, \mathrm{P}=0.036)$. In addition, no effect of rebamipide gargle on tumour response to chemoradiotherapy was recognized compared with the placebo group.

Conclusions: For patients with oral cancer undergoing chemoradiotherapy, rebamipide gargle may contribute to decrease the severity of oral mucositis.
\end{abstract}

Keywords: oral mucositis; chemotherapy; radiotherapy; rebamipide; oral cancer.

Accepted for publication: 28 November 2011

To cite this article:

Yasuda T, Chiba H, Satomi T, Matsuo A, Kaneko T, Chikazu D, Miyamatsu H. Chemoradiotherpy-Induced Oral Mucositis in Patients with Oral Cancer: a Pilot Study.

J Oral Maxillofac Res 2011 (Oct-Dec);2(4):e3

URL: http://www.ejomr.org/JOMR/archives/2011/4/e3/v2n4e3ht.pdf

doi: $10.5037 /$ jomr.2011.2403 


\section{INTRODUCTION}

Cancer chemotherapy and radiotherapy have various significant adverse effects, including oral mucositis, which is a painful condition and risk factor for infection that can lead to impaired nutritional status and inadequate hydration, significantly impairing the patients' quality of life. Furthermore, in some patients, it becomes a dose-limiting toxicity, slowing or preventing continuation of cancer treatment [1].

Oral mucositis is frequently observed in patients with cancer receiving high-dose head and neck radiotherapy $(85-100 \%)$, stem cell transplantation $(75-100 \%)$, or standard-dose chemotherapy for solid tumours (5 - 40\%). Moreover, combined use of chemotherapy and radiotherapy (chemoradiotherapy) for patients with head and neck cancer may increase the incidence and severity of oral mucositis [2].

Although the clinical features of oral mucositis are mainly the result of oral epithelial injury, it is believed that oral mucositis is due to various causes, including induction of direct epithelial cell injury and DNA strand breaks by anti-neoplastic drugs or radiation, extensive cell injury resulting from the generation of reactive oxygen species (free radicals) and cytotoxic cytokines (IL-8, IL-1 $\beta$, and TNF- $\alpha$ ), infection, myelosuppression, and xerostomia $[4,5]$. The pathogenetic sequence of oral mucositis has been proposed by Sonis et al. [] to include the following five steps: 1) an initiation stage, 2) up-regulation and generation of messenger signals,

3) signaling and amplification, 4) ulceration, and 5) a healing stage.

Rebamipide (Mucosta ${ }^{\circledR}$, Tokyo, Japan) is a drug developed in Japan for the treatment of gastritis and gastric ulcer. The mechanisms involved in the antiulcer and cytoprotective effects of rebamipide have been reported to include induction of prostaglandin E2 synthesis via COX-2 expression [7], up-regulation of growth factors and their receptors such as EGF [8] and HGF [9], induction of mucus secretion [10], anti-freeradical effects $[11, \underline{12}]$, and inhibition of the production of inflammatory cytokines such as IL-1, IL-8, and TNF- $\alpha[\underline{13}, \underline{14}]$.

The mechanisms of onset of oral mucositis associated with chemoradiotherapy, which include production of free radicals, increase of inflammatory cytokines, and alteration of intracellular signal transduction, suggest that rebamipide should be useful for its treatment and prevention.

Thus, we designed a randomised, double-blind, placebocontrolled trial of rebamipide gargle solution in patients with head and neck cancer. The primary objective of this study was to determine whether topical rebamipide effectively reduced the severity of oral mucositis induced by chemoradiotherapy.

\section{MATERIAL AND METHODS}

\section{Study design and patient eligibility}

The study design and informed consent disclosure were approved by the Institutional Ethics Committee of Tokyo Medical University and in accordance with the percepts established by the Helsinki Declaration. Patients declared their willingness to participate in the study once the details of the study and the treatment involved had been explained to them.

The subjects were patients with cancer of the oral cavity who visited the Department of Oral and Maxillofacial Surgery (Tokyo Medical University Hospital), and were scheduled to receive chemoradiotherapy between January 2005 and May 2008. All patients in this study were older than 20 years of age, had normal renal and liver functions, and were required to have a Karnofsky performance status ranging between 90 and $100 \%$. Both primary radical chemoradiotherapy and preoperative chemoradiotherapy patients were eligible for enrolment. In addition, patients with recurrence of cancer of the oral cavity were eligible. Exclusion criteria included insulin-dependent diabetes, use of non-steroidal antiinflammatory drugs or aspirin, use of dentures, and allergy to rebamipide. All patients enrolled in the study gave their written informed consent. All patients had the right to withdraw from the study at any time. In this prospective, double-blind, placebo-controlled study, patients were assigned to the groups by computer-based 1:1 ratio randomization to receive either rebamipide gargle or placebo solution. A total of 24 patients met the inclusion and exclusion criteria. All patients were treated with $2 \mathrm{~Gy} /$ fraction for at least 4 weeks using conventional radiation techniques as both primary radical and preoperative therapy. Chemotherapy was scheduled as weekly $10 \mathrm{mg} / \mathrm{m}^{2}$ docetaxel infusion for 4 weeks (Days 1, 8, 15, and 22). Standard oral and dental care was provided to all patients during the study.

\section{Gargle solutions and gargling methods}

The gargle solution was prepared by the method of Hanawa et al. [15]. A one-day volume $(300 \mathrm{~mL})$ of rebamipide gargle solution contained $300 \mathrm{mg}$ of rebamipide, as well as $3.0 \mathrm{~g}$ of Alcox E- $30^{\circledR}$ resin (Meisei Chemical Co., Kyoto, Japan ), which is a polymerized ethylene oxide (M.W. 300,000 - 500,000), and $1.2 \mathrm{~g}$ of Inagel F-13 ${ }^{\circledR}$ (Ina Food Industry Co., Ltd. Nagano, Japan), which is a mixture of agar, 
carageenan, and xanthan gum, to enhance the viscosity and dispersion of solutions, with the addition of methyl parahydroxybenzoate (Koso Chemical Co., Ltd., Tokyo, Japan) and propyl parahydroxybenzoate $0.04 \mathrm{~g}$ (reagent supplied by Koso Chemical Co., Ltd., Tokyo) as preservatives (Table 1). In addition, $6 \mathrm{~mL}$ of $4 \%$ lidocaine was added to the gargle solutions. The placebo gargle solution contained all ingredients except for rebamipide. The gargle solution, at $300 \mathrm{~mL}$ per bottle for one day, was used in 6 divided doses, i.e., $50 \mathrm{~mL}$ after every meal, as well as at 10 a.m., 3 p.m., and before going to bed. Subjects were instructed to gargle for 2-3 minutes each time, and not to rinse out the gargle with water for 10 minutes after each gargle. This gargle solution can be stored for a maximum of 3 weeks, according to the results of the investigation performed by the Department of Pharmacy of the hospital (data not shown). Because of the bitterness of lidocaine and rebamipide, pineapple flavor was added and dissolved immediately before use of both types of gargle solutions. All subjects received an information sheet describing how to use the gargle solution, and were given a full explanation before starting the study. Gargling was started at the initiation of radiotherapy and was continued until final irradiation.

\section{Study endpoints and statistics}

After the initiation of gargling, the same study physician, who was blinded to the solution used by each patient, evaluated them every other week. Grading of oral mucositis was performed using the WHO oral toxicity scale [16] of 0 - 4 (0: normal, no mucositis; 1 : soreness and erythema; 2: erythema, ulcers, can eat solids; 3: ulcers, requires liquid diet only; 4: alimentation not possible). The primary endpoint of the study was the incidence of severe mucositis (WHO grade 3 or 4) after 4 weeks on chemoradiotherapy because in our previous study [17] we found the peak frequency of oral mucositis ( $\geq$ WHO Grade 3 ) at this time point. Patients who were used drip-feed therapy included Grade 4. Tumour response to chemoradiotherapy was assessed by the Response Evaluation Criteria in Solid Tumours (RECIST) [1] $]$, 4 weeks after the end of chemoradiotherapy. The effective response rate (complete response + partial response) in each group was also evaluated. When data were not available, we used the last-observation-carried-forward strategy for intention-to-treat analysis (LOCF-ITT).

\section{Statistical analysis}

Differences between the two groups were evaluated by Mann-Whitney test for continuous variables, Fisher's
Table 1. Rebamipide Gargle solution for 1-day volume

\begin{tabular}{ll}
\hline Rebamipide & $0.3 \mathrm{~g}$ \\
Alkox E- $30^{\circledR}$ (polymerised ethylene oxide) & $3.0 \mathrm{~g}$ \\
$\begin{array}{l}\text { Inagel F-13 } \\
\text { carageenan) }\end{array}$ & $1.2 \mathrm{~g}$ \\
Methyl parahydroxybenzoate & $0.08 \mathrm{~g}$ \\
Propyl parahydroxybenzoate & $0.04 \mathrm{~g}$ \\
$4 \%$ Lidocaine hydrochloride & $6 \mathrm{ml}$ \\
Distilled water & Total \\
& $300 \mathrm{~mL}$ \\
\hline
\end{tabular}

exact test and Monte Carlo test for categorical variables. $\chi^{2}=$ Chi-Square test was applied for nonparametric variables. The $\mathrm{P}$ values cited are two-sided, and when less than 0.05 were considered significant.

\section{RESULTS}

A total of 24 patients were enrolled in this study. Of these, 12 were in the rebamipide gargle arm and 12 in the placebo arm. Their characteristics before treatment are shown in Table 2. They consisted of 14 men and 10 women, whose age ranged from 32 to 82 years (mean $=60$ years). The mean age of the rebamipide group was lower than that of the placebo group, but there was no significant differences $(P=0.077)$. Although the rebamipide group had more Stage I and II patients and the placebo group more stage IV patients, there were no significant differences between the two arms either in stage or other parameters. In addition, there were no differences between the two arms in T size and leukocyte or neutrophil count.

Patients in both arms reported good treatment compliance, with no complaints regarding taste. Two patients in the placebo group dropped out after 30 Gy radiation because they were unable to continue gargling due to severe (grades 3 and 4) oral mucositis. Chemoradiotherapy was continued for the two patients who dropped out. On the basis of LOCF criteria, the WHO score of two dropped out patients at the end of 30 Gy were adopted at the end of score of $40 \mathrm{~Gy}$. No patient developed grade $\geq 3$ oral mucositis in the rebamipide group by the end of 30 Gy radiation, compared to 4 patients $(33.3 \%)$ in the placebo group (not significant: $\mathrm{P}=0.11$ ). All patients in both groups developed grade $\geq 2$ oral mucositis by the end of 40 Gy radiation therapy (primary endpoint), as shown in Table 3. As for the incidence of Grade 3 - 4 oral mucositis, $83 \%$ of the patients in the placebo group developed grade $\geq 3$ oral mucositis, compared to $33.3 \%$ in the rebamipide group ( $\mathrm{P}=0.036)$ (Figure 2 and Table 3 ). In addition, the tumour response to chemoradiotherapy was not affected by rebamipide gargle, as shown in Table 4. 
Table 2. Patient background

\begin{tabular}{|c|c|c|c|c|}
\hline & & Placebo gargle & Rebamipide gargle & $\mathbf{P}$ \\
\hline \multicolumn{2}{|c|}{ Sex (Male/Female) } & $7 / 5$ & $7 / 5$ & \\
\hline \multirow{6}{*}{$\begin{array}{c}\text { Age } \\
\text { (years) }\end{array}$} & $31-40$ & 0 & 2 & \multirow{6}{*}{$\begin{array}{c}\chi^{2}=6.8 \\
d f=5 \\
P=0.238^{b}\end{array}$} \\
\hline & $41-50$ & 0 & 2 & \\
\hline & $51-60$ & 5 & 5 & \\
\hline & $61-70$ & 2 & 2 & \\
\hline & $71-80$ & 4 & 1 & \\
\hline & $81-90$ & 1 & 0 & \\
\hline Mean a & e (SD) & $65.9(10.8)$ & $54.9(11.5)$ & $0.077^{\mathrm{b}}$ \\
\hline \multicolumn{5}{|c|}{ Primary site of cancer } \\
\hline Maxi & ary gingiva & 3 & 2 & \multirow{5}{*}{$\begin{array}{c}\chi 2=3.7 \\
\mathrm{df}=4 \\
\mathrm{P}=0.522^{\mathrm{b}}\end{array}$} \\
\hline Mand & bular gingiva & 4 & 3 & \\
\hline Tong & & 2 & 6 & \\
\hline Oral & & 2 & 1 & \\
\hline Bucc & mucosa & 1 & 0 & \\
\hline Initial/r & lapse & $11 / 1$ & $11 / 1$ & \\
\hline \multicolumn{5}{|c|}{ Stage of cancer } \\
\hline Stage & & 0 & 4 & \multirow{4}{*}{$\begin{array}{c}\chi 2=6.0 \\
\mathrm{df}=3 ; \\
\mathrm{P}=0.125^{\mathrm{b}}\end{array}$} \\
\hline Stage & & 4 & 4 & \\
\hline Stage & & 1 & 1 & \\
\hline Stage & & 6 & 2 & \\
\hline \multicolumn{5}{|c|}{$T$ size of cancer } \\
\hline $\mathrm{T}_{1}$ & & 0 & 4 & \multirow{4}{*}{$\begin{array}{c}\chi^{2}=7.2 \\
d f=3 \\
P=0.065^{b}\end{array}$} \\
\hline $\mathrm{T}_{2}$ & & 5 & 5 & \\
\hline $\mathrm{T}_{3}$ & & 3 & 2 & \\
\hline $\mathrm{T}_{4}$ & & 3 & 0 & \\
\hline \multicolumn{2}{|c|}{$\mathrm{WBC}^{\text {a }}$ count at baseline, mean (SD) } & $6.56(1.83)$ & $5.80(2.15)$ & $0.34^{\mathrm{b}}$ \\
\hline \multicolumn{2}{|c|}{ Neutrophil ${ }^{\text {a }}$ count at baseline, mean (SD) } & $3.94(1.37)$ & $3.61(2.15)$ & $0.48^{\mathrm{b}}$ \\
\hline
\end{tabular}

${ }^{\mathrm{a} \times} \times 10^{3}$ cells $/ \mathrm{mm}^{3}$.

${ }^{b}$ No statistically significant at the level $\mathrm{P}<0.05$ (Monte Carlo test).

$\mathrm{SD}=$ Standard deviation; $\mathrm{WBC}=$ White Blood Cell; $\chi 2=$ Chi-Square .

Table 3. Incidence of oral mucositis after radiotherapy for oral cancer

\begin{tabular}{|c|c|c|c|c|c|c|c|}
\hline \multirow{2}{*}{$\begin{array}{l}\text { Incidence of oral mucositis } \\
\text { (WHO) grade }\end{array}$} & \multicolumn{3}{|c|}{$\begin{array}{l}\text { Placebo gargle } \\
\quad(\mathrm{n}=12)\end{array}$} & \multicolumn{3}{|c|}{$\begin{array}{l}\text { Rebamipide gargle } \\
\qquad(\mathrm{n}=12)\end{array}$} & \multirow{2}{*}{$\begin{array}{c}P^{\mathrm{a}} \\
(\text { after } 40 \mathrm{~Gy})\end{array}$} \\
\hline & 20 Gy & 30 Gy & 40 Gy & 20 Gy & 30 Gy & 40 Gy & \\
\hline Grade 0 & 4 & 0 & 0 & 8 & 1 & 0 & \\
\hline Grade 1 & 4 & 0 & 0 & 2 & 2 & 0 & \\
\hline Grade 2 & 4 & 8 & 2 & 2 & 9 & 8 & \\
\hline Grade 3 & 0 & 3 & 7 & 0 & 0 & 3 & \\
\hline Grade 4 & 0 & 1 & 3 & 0 & 0 & 1 & \\
\hline$\%$ Grade 3 or 4 & 0 & 33.3 & 83.3 & 0 & 0 & 33.3 & $0.036^{\mathrm{a}}$ \\
\hline
\end{tabular}

${ }^{\text {aagnificant }}$ at the level $\mathrm{P}<0.05$ (Fisher's exact test).

$\mathrm{WHO}=$ World Health Organization . 
Table 4. Effect of rebamipide on the response rate to chemoradiotherapy in oral cancer patients

\begin{tabular}{cccc}
\hline Response rate & $\begin{array}{c}\text { Placebo gargle } \\
(\mathbf{n}=\mathbf{1 2})\end{array}$ & $\begin{array}{c}\text { Rebamipide gargle } \\
(\mathbf{n}=\mathbf{1 2})\end{array}$ & $\mathbf{P}$ \\
\cline { 2 - 3 } & $\mathbf{N}(\mathbf{\%})$ & $\mathbf{N}(\mathbf{\%})$ & \\
\hline Complete response & $1(8.3)$ & $2(16.7)$ & $\begin{array}{c}\chi^{2}=1.5 ; \\
\mathrm{df}=2 ; \\
\mathrm{P}=0.594^{\mathrm{a}}\end{array}$ \\
\hline Partial response & $11(91.7)$ & $9(75)$ & \\
\hline Stable disease & 0 & $1(8.3)$ & \\
\hline
\end{tabular}

${ }^{a}$ No statistically significant at the level $\mathrm{P}<0.05$ (Monte Carlo exact test). $\chi^{2}=$ Chi-Square.

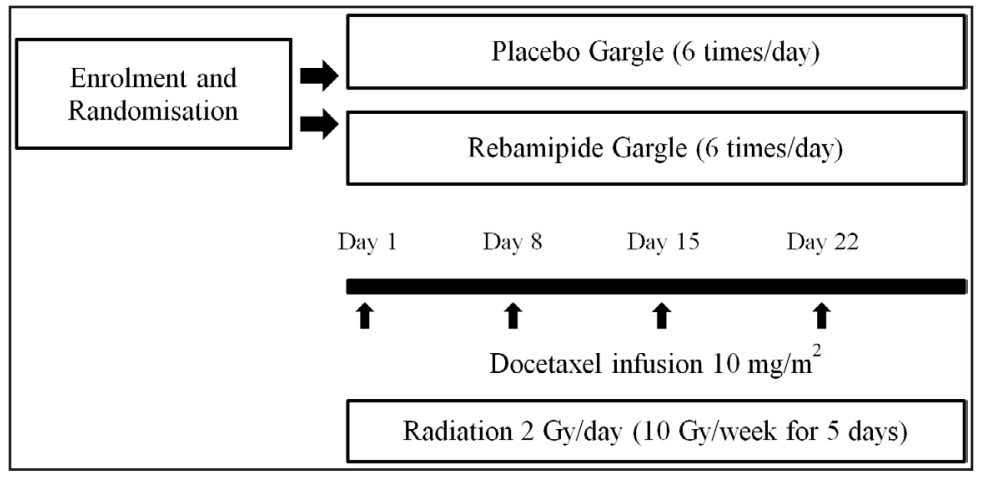

Figure 1. Schedule of chemoradiotherapy and oral treatment.

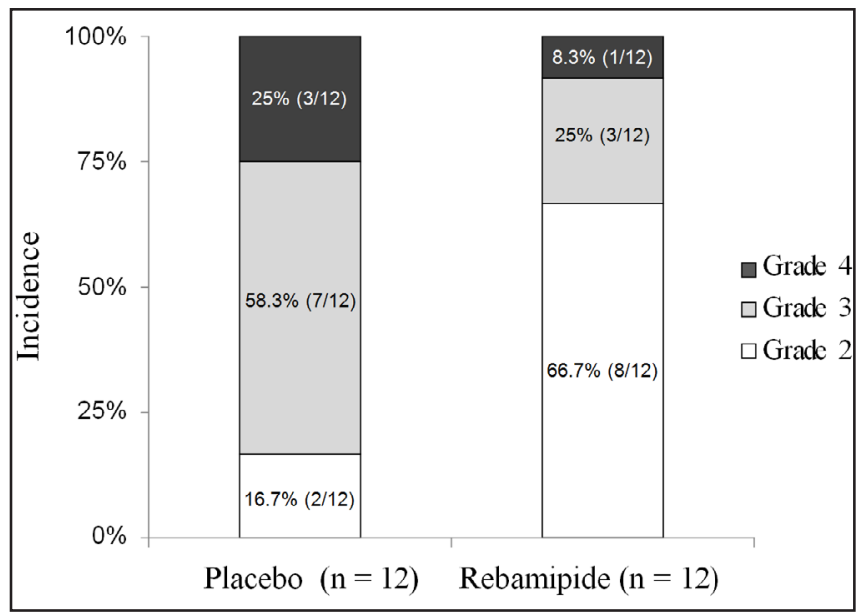

Figure 2. Incidence and severity of oral mucositis after chemotherapy plus 40 Gy radiotherapy.

There were no patients who were used gastric fistula. No adverse effects related to the drug or the infusions were noted in either group.

\section{DISCUSSION}

Over the past 20 years, while supportive care for adverse effects of cancer treatment such as nausea, vomiting, and myelosuppression has markedly improved, prevention and treatment of oral mucositis have been only minimally improved. A comprehensive understanding of the pathogenesis of oral mucositis induced by chemotherapy, radiotherapy and chemoradiotherapy, together with a clear definition of risk factors for development and severity of the lesion, remain under investigation. Multiple risk factors have been reported for the development of oral mucositis, which Eilers and Million [19] classified into two categories: therapy-related factors, and patient-related factors. In their classification, therapy-related risk factors are subdivided into five categories: 1) specific chemotherapy/biotherapy agents, 2) doses of agents and administration schedule, 3) type of transplant, 4) radiation site and fractionation of radiation, and 5) combined-modality therapy. In particular, use of chemotherapy with new anticancer drugs combined with radiotherapy is expected to be effective to treat head and neck cancer. Chemoradiotherapy is intended to exert synergistic cytotoxic effects on cancer cells, but it injures normal cells as well. Vera-Llonch et al. [3] reported that cumulative radiation of $>50$ Gy was a risk factor for oral mucositis in head and neck cancer. In the present study, chemotherapy was performed with docetaxel, which has been described as highly effective for head and neck cancer [20], and oral mucositis occurred in the placebo group after delivery of radiation to $20 \mathrm{~Gy}$, with onset of Grade 1 - 2 oral mucositis in $8(66.7 \%)$ of 12 patients. It thus appeared that oral mucositis was enhanced by the combined use of radiotherapy and docetaxel. Furthermore, it was reported that the incidence of severe oral mucositis was 13\% after docetaxel monotherapy, compared to $98 \%$ after combined treatment with radiation, indicating a striking increase in the incidence of oral mucositis after combined treatment [6]. In the present study as well, the incidence of severe oral mucositis at completion of delivery of radiation to $40 \mathrm{~Gy}$, the primary endpoint of this study, was $83 \%$ in the placebo group, indicating that combined use of radiotherapy and docetaxel is a significant risk factor for the development of severe oral mucositis. The dose of anti-tumour drugs or radiation therapy was not decreased in any patient during this study; however, Kodaira et al. [21] reported dose-limiting toxicity with the same regimen in patients with head and neck cancer. On the other hand, patient-related factors include: 1) age, 2) gender, 3) oral health and hygiene, 4) secretory function of salivary glands, 5) genetic factors, 6) body mass index, 7) renal function, 8) smoking, and 9) previous cancer treatment. 
In the present study, the randomisation performed at the start of the study did not involve stratification based on age, as a result of which the rebamipide group consisted of slightly younger patients (Table 2). There have been reports of a higher incidence of severe oral mucositis in patients of advanced age among those receiving 5-FU $[\underline{5}, \underline{22}]$. But in case of chemoradiotherapy of head and neck cancer, high incidences of severe oral mucositis have been reported in younger patients by both VeraLlonch et al. [3] and van den Broek et al. [23]. Although the relationship between age and risk for oral mucositis remains unclear, it appears that younger patients with head and neck cancer are indeed at a higher risk for oral mucositis.

In the present study, use of rebamipide reduced the incidence of oral mucositis by half at completion of radiation to 20 Gy compared with placebo, and significantly reduced the incidence of severe oral mucositis at completion of radiation to 40 Gy (Figure 2 and Table 3), indicating a prophylactic effect of rebamipide. Palifermin, N-truncated recombinant human keratinocyte growth factor-1, is the first drug to be approved in the world for intervention in patients with oral mucositis following an aggressive conditioning regimen requiring haematopoietic stemcell transplantation for haematologic cancer [24]. In Japan, because palifermin has not been launched, various conventional and empiric ameliorative treatments are used in addition to basic oral care and cryotherapy, including the following drugs and supplements: vitamins (A, C, and E), sodium alginate, glutathione, azulene, glutamine, sucralfate, prostaglandins, Chinese herbal drugs, allopurinol, and cryotherapy with fibrinolysin/deoxyribonuclease ice balls. Although there are no widely accepted clinical data regarding effective prevention or treatment of oral mucositis, allopurinol gargle is widely used for preventing oral mucositis in Japan. Allopurinol is believed to protect cells from reactive oxygen species (ROS), since it can suppress the production of superoxide (O2-) by inhibiting xanthine oxidase. Rebamipide also inhibits ROS, via two mechanisms: inhibiting superoxide production [11], and scavenging hydroxyl radicals [12]. Superoxide itself is a relatively weak cytotoxic radical, but is also a precursor of peroxynitrite and hydroxyl radicals, which are highly toxic. Thus, in terms of induction of scavenging of ROS, which play an important role in the initiation of oral mucositis, rebamipide is considered more useful than allopurinol. In addition, while activation of inflammatory responses and associated production of cytotoxic inflammatory cytokines are considered important in the cycle of exacerbation of oral mucositis, rebamipide is known to inhibit IL-8 production by inhibiting its transcription factor NFK-B, an important trigger of this condition [13]. The efficacy of rebamipide demonstrated in the present study may be the result of suppression of the following three stages of the onset of oral mucositis suggested by Sonis et al. [6]: 1) the initiation stage, 2) up-regulation and generation of messenger signals, and 3) signalling and amplification. On the other hand, there has been concern that the effects of rebamipide on COX-2 []], PGE2 []], and EGF [9] might influence cancer cell growth. However, since rebamipide did not influence tumour response to chemoradiotherapy, it did not appear to influence its therapeutic efficacy. Kawai et al. [25] reported that oral administration of rebamipide did not influence the antitumour effect of fluorouracil drugs in the Yoshida Sarcoma-bearing rat. Furthermore, Haagen et al. [26] recently reported that administration of infliximab (TNF- $\alpha$ antibody) and celecoxib (selective COX-2 inhibitor) did not affect the onset and aggravation of radiation-induced oral ulcers. It thus appears that these inflammatory pathways are not involved in the onset and development of oral mucositis.

\section{CONCLUSIONS}

The findings of this randomised study suggest that rebamipide gargle solution may be an effective means to reduce the severity of chemoradiation-induced oral mucositis in oral cancer patients. Although it remains unclear which of the various mechanisms of action of rebamipide contributed to the efficacy of this drug in the present study, rebamipide appears to be a drug with a unique profile in relation to the pathophysiology of oral mucositis induced by chemotherapy or radiotherapy. A further clinical trial in a large number of patients is needed to confirm our findings.

\section{ACKNOWLEDGMENTS AND DISCLOSURE STATEMENTS}

The authors declare that they have no conflict of interests. 


\section{REFERENCES}

1. Kolokythas A. Long-term surgical complications in the oral cancer patient: A comprehensive review. Part II. J Oral Maxillofac Res. 2010 July-Sep;1(3):e2. URL: http:/www.ejomr.org/JOMR/archives/2010/3/e2/e2ht.htm; [doi: 10.5037/jomr.2010.1302]

2. Peterson DE. New strategies for management of oral mucositis in cancer patients. J Support Oncol. 2006 Feb;4 (2 Suppl 1) :9-13. [Medline: 16499139]

3. Vera-Llonch M, Oster G, Hagiwara M, Sonis S. Oral mucositis in patients undergoing radiation treatment for head and neck carcinoma. Cancer. 2006 Jan 15;106(2):329-36.[Medline: 16342066] [doi: 10.1002/cncr.21622]

4. Sonis ST. Pathobiology of oral mucositis: novel insights and opportunities. J Support Oncol. 2007 Oct;5 (9 Suppl 4):3-11. [Medline: 18046993]

5. McCarthy GM, Awde JD, Ghandi H, Vincent M, Kocha WI. Risk factors associated with mucositis in cancer patients receiving 5-fluorouracil. Oral Oncol. 1998 Nov;34(6):484-90. [Medline: 9930359] [doi: 10.1016/S1368-8375(98)00068-2]

6. Sonis ST, Elting LS, Keefe D, Peterson DE, Schubert M, Hauer-Jensen M, Bekele BN, Raber-Durlacher J, Donnelly JP, Rubenstein EB. Mucositis Study Section of the Multinational Association for Supportive Care in Cancer; International Society for Oral Oncology. Perspectives on cancer therapy-induced mucosal injury: pathogenesis, measurement, epidemiology, and consequences for patients. Cancer. 2004 May 1;100(9 Suppl):1995-2025. [Medline: 15108222] [doi: $10.1002 /$ cncr.20162]

7. Sun WH, Tsuji S, Tsujii M, Gunawan ES, Kawai N, Kimura A, Kakiuchi Y, Yasumaru M, Iijima H, Okuda Y, Sasaki Y, Hori M, Kawano S. Induction of cyclooxygenase-2 in rat gastric mucosa by rebamipide, a mucoprotective agent. J Pharmacol Exp Ther. 2000 Nov;295(2):447-52. [Medline: 11046075]

8. Tarnawski A, Arakawa T, Kobayashi K. Rebamipide treatment activates epidermal growth factor and its receptor expression in normal and ulcerated gastric mucosa in rats: one mechanism for its ulcer healing action? Dig Dis Sci. 1998 Sep;43(9 Suppl):90S-98S. [Medline: 9753233]

9. Udagawa A, Shiota G, Ichiba M, Murawaki Y. Effect of rebamipide on acetic acid-induced gastric ulcer in rats: involvement of hepatocyte growth factor. Scand J Gastroenterol. 2003 Feb;38(2):141-6. [Medline: 12678329] [doi: 10.1080/00365520310000609]

10. Ishihara K, Komuro Y, Nishiyama N, Yamasaki K, Hotta K. Effect of rebamipide on mucus secretion by endogenous prostaglandin-independent mechanism in rat gastric mucosa. Arzneimittelforschung. 1992 Dec;42(12):1462-6. [Medline: 1337697]

11. Kim CD, Hong KW. Preventive effect of rebamipide on gastric lesions induced by ischemia-reperfusion in the rat. $\mathrm{J}$ Pharmacol Exp Ther. 1995 Oct;275(1): 340-4. [Medline: 7562569]

12. Yoshikawa T, Naito Y, Tanigawa T, Kondo M. Free radical scavenging activity of the novel anti-ulcer agent rebamipide studied by electron spin resonance. Arzneimittelforschung. 1993 Mar;43(3):363-6. [Medline: 8387788]

13. Masamune A, Yoshida M, Sakai Y, Shimosegawa T. Rebamipide inhibits ceramide-induced interleukin-8 production in Kato III human gastric cancer cells. J Pharmacol Exp Ther. 2001 Aug;298(2):485-92. [Medline: 11454909] [FREE Full Text]

14. Katada K, Yoshida N, Isozaki Y, Tomatsuri N, Ichikawa H, Naito Y, Okanoue T, Yoshikawa T. Prevention by rebamipide of acute reflux esophagitis in rats. Dig Dis Sci. 2005 Oct;50 Suppl 1:S97-S103. [Medline: 16184428] [doi: $10.1007 / \mathrm{s} 10620-005-2813-4]$

15. Hanawa T, Masuda N, Mohri K, Kawata K, Suzuki M, Nakajima S. Development of patient-friendly preparations: preparation of a new allopurinol mouthwash containing polyethylene(oxide) and carrageenan. Drug Dev Ind Pharm. 2004 Feb;30(2):151-61.[Medline: 15089049] [doi: 10.1081/DDC-120028710]

16. Miller AB, Hoogstraten B, Staquet M, Winkler A. Reporting results of cancer treatment. Cancer. 1981 Jan;47(1):207-14. [Medline: 7459811] [doi: 10.1002/1097-0142(19810101)47:1<207::AID-CNCR2820470134>3.0.CO;2-6]

17. Yasuda T, Chiba H, Satomi T, MatsuoA, Kaneko T, Miyamatsu H. [Apilot study of rebamipide-gargle for chemoradiotherapyinduced mucositis in oral cancer patients] Gan To Kagaku Ryoho. 2008 Jul;35(7):1157-61. [Medline: 18633254]

18. Mazumdar M, Smith A, Schwartz LH. A statistical simulation study finds discordance between WHO criteria and RECIST guideline. J Clin Epidemiol. 2004 Apr;57(4):358-65. [Medline: 15135836] [doi: 10.1016/j.jclinepi.2003.07.015]

19. Eilers J, Million R. Prevention and management of oral mucositis in patients with cancer. Semin Oncol Nurs. 2007 Aug;23(3):201-12. [Medline: 17693347] [doi: 10.1016/j.soncn.2007.05.005]

20. Nabell L, Spencer S. Docetaxel with concurrent radiotherapy in head and neck cancer. Semin Oncol. 2003 Dec;30(6 Suppl 18):89-93. [Medline: 14727247] [doi: 10.1053/j.seminoncol.2003.11.017]

21. Kodaira T, Fuwa N, Furutani K, Tachibana H, Yamazaki T. Phase I trial of weekly docetaxel and concurrent radiotherapy for head and neck cancer in elderly patients or patients with complications. Jpn J Clin Oncol. 2005 Apr;35(4):173-6. [Medline: 15845564] [doi: 10.1093/jico/hyi058] [FREE Full Text] 
22. Zalcberg J, Kerr D, Seymour L, Palmer M. Haematological and non-haematological toxicity after 5-fluorouracil and leucovorin in patients with advanced colorectal cancer is significantly associated with gender, increasing age and cycle number. Tomudex International Study Group. Eur J Cancer. 1998 Nov;34(12):1871-5. [Medline: 10023308] [doi: 10.1016/S0959-8049(98)00259-7]

23. van den Broek GB, Balm AJ, van den Brekel MW, Hauptmann M, Schornagel JH, Rasch CR. Relationship between clinical factors and the incidence of toxicity after intra-arterial chemoradiation for head and neck cancer. Radiother Oncol. 2006 Nov;81(2):143-50. [Medline: 17055096] [doi: 10.1016/j.radonc.2006.09.002]

24. Blijlevens N, Sonis S. Palifermin (recombinant keratinocyte growth factor-1): a pleiotropic growth factor with multiple biological activities in preventing chemotherapy- and radiotherapy-induced mucositis. Ann Oncol. 2007 May;18(5):817-26. Epub 2006 Oct 9. [Medline: 17030544] [doi: 10.1093/annonc/md1332] [FREE Full Text]

25. Kawai K, Asakuni T, Ishiyama H, Azuma A, Otsuji S, Ichikawa H, Ono Y, Takizawa H, Sekiguchi K. Rebamipide does not interfere with the antitumor effect of UFT in a Yoshida Sarcoma Transplant Model. Iyakuhin Kenkyu. 2001;32(2):51-57.

26. Haagen J, Krohn H, Röllig S, Schmidt M, Wolfram K, Dörr W. Effect of selective inhibitors of inflammation on oral mucositis: preclinical studies. Radiother Oncol. 2009 Sep;92(3):472-6. Epub 2009 Jul 1. [Medline: 19576646] [doi: 10.1016/j.radonc.2009.06.006]

\section{To cite this article:}

Yasuda T, Chiba H, Satomi T, Matsuo A, Kaneko T, Chikazu D, Miyamatsu H. Preventive Effect of Rebamipide Gargle on Chemoradiotherpy-Induced Oral Mucositis in Patients with Oral Cancer: a Pilot Study.

J Oral Maxillofac Res 2011;2(4):e3

URL: http://www.ejomr.org/JOMR/archives/2011/4/e3/v2n4e3ht.pdf

doi: $10.5037 /$ jomr.2011.2403

Copyright (C) Yasuda T, Chiba H, Satomi T, Matsuo A, Kaneko T, Chikazu D, Miyamatsu H. Accepted for publication in the JOURNAL OF ORAL \& MAXILLOFACIAL RESEARCH (http://www.ejomr.org), 28 November 2011.

This is an open-access article, first published in the JOURNAL OF ORAL \& MAXILLOFACIAL RESEARCH, distributed under the terms of the Creative Commons Attribution-Noncommercial-No Derivative Works 3.0 Unported License, which permits unrestricted non-commercial use, distribution, and reproduction in any medium, provided the original work and is properly cited. The copyright, license information and link to the original publication on (http://www.ejomr.org) must be included. 